\title{
OS IMPACTOS DO CÓDIGO DE PROCESSO CIVIL NA DURAÇÃO RAZOÁVEL DO PROCESSO: UM BALANÇO DA SUA VIGÊNCIA
}

\section{THE IMPACTS OF THE CIVIL PROCEDURE CODE IN REASONABLE DURATION OF PROCESS: A BALANCE OF ITS TERM}

\section{Larissa Clare Pochmann da Silva ${ }^{1}$}

\section{Resumo}

O presente artigo objetiva analisar os impactos trazidos pelo Código de Processo Civil de 2015 no tempo de tramitação dos processos. Inicialmente, busca retratar o significado do tema que será abordado, isto é, a duração razoável para o processo, indicando a insuficiência de critérios meramente quantitativos. Em seguida, destaca as previsões do Código de Processo Civil de 2015 que podem interferir na duração razoável do processo e, após, a partir de dados do Conselho Nacional de Justiça (CNJ), que abrangem o ano anterior e o período de vigência do diploma processual, interpreta a alteração no tempo de tramitação das demandas, observando-se que, ainda que, nos primeiros anos de vigência do codex, o tempo de tramitação dos processos tenha aumentado consideravelmente, a perspectiva é a de que, a médio prazo, acabe por se ter um tempo inferior de tramitação, se comparado ao registrado antes de sua vigência.

Palavras-chave. Duração razoável do processo; Código de Processo Civil de 2015; impactos; balanço; perspectivas.

SUMÁRIO: Introdução. 1. A garantia da duração razoável do processo. 2. O Código de Processo Civil de 2015. 3. Os impactos do código no tempo médio de tramitação dos processos. 3.1. Os dados sobre a duração razoável do processo. 3.2. Os reflexos do diploma na duração razoável do processo. Conclusão. Referências Bibliográficas.

\section{Introdução}

A garantia fundamental da duração razoável do processo, insculpida, a partir da Emenda $n^{\circ} 45 / 2004$, no artigo $5^{\circ}$, inciso LXXVIII, da Constituição Federal, é tema que não é recente, nem

\footnotetext{
${ }^{1}$ Pós-Doutoranda em Direito Processual pela Universidade do Estado do Rio de Janeiro (UERJ). Doutora e Mestre em Direito pela Universidade Estácio de Sá (UNESA). Graduada em Direito pela Universidade do Estado do Rio de Janeiro (UERJ). Professora da Universidade Estácio de Sá (UNESA) e da Universidade Cândido Mendes (UCAM). Advogada. Universidade Candido Mendes - UCAM, Rio de Janeiro - Brasil. ORCID iD: https://orcid.org/0000-0002-1537-9418 Lattes: http://lattes.cnpq.br/2580346811153197 E-mail: larissacpsilva@gmail.com
} 
peculiar ao cenário brasileiro, mas que assume inegável relevância diante da vultosa atuação do Poder Judiciário para a tutela dos direitos fundamentais e implementação de políticas públicas.

O Código de Processo Civil de 2015, que teve entre um de seus objetivos o estabelecimento de uma sintonia fina com a Constituição, deve buscar um ponto de equilíbrio entre a participação e a duração razoável do processo.

Considerando que o Código entrou em vigor no dia 18 de março de 2016, objetiva-se fazer um balanço de sua vigência, com uma abordagem quanti-qualitativa, de forma a se destacar se o novo diploma contribuiu para a duração razoável dos processos.

Para isso, inicia-se abordando o significado da duração razoável dos processos, com a ênfase à insuficiência de conceitos estritamente quantitativos. Em seguida, destacam-se os institutos trazidos pelo novo diploma e, por fim, analisam-se os dados sobre a duração razoável do processo disponibilizados pelo Conselho Nacional de Justiça (CNJ), a fim de analisar a duração dos processos que atualmente tramitam no Poder Judiciário, avaliando-se se o princípio constitucional tem sido realizado.

\section{A garantia da duração razoável do processo}

Diversos países vivenciam, na atualidade, o que se denomina de crise da justiça civil (ZUCKERMAN, 2013, p. 61). Esse cenário, que não é restrito ao Brasil (BARBOSA MOREIRA, 2007, p. 369), caracteriza-se por duas vertentes, que estão umbilicalmente relacionadas: 1) pelos indicativos da ineficiência de resultados, diante da excessiva duração dos processos, em virtude da ampliação do número de demandas que ingressam no Poder Judiciário, em descompasso com o quantitativo de recursos materiais e humanos (MENDES, 2014, p. 33-34); e 2) por uma acentuada pela dificuldade de os julgadores examinarem atentamente o conteúdo de todos os atos do processo.

A denominada crise da justiça se relaciona, portanto, à necessidade de se assegurar uma duração razoável do processo, em compasso com o respeito às garantias constitucionais do processo, especialmente o contraditório participativo, proporcionando-se a possibilidade de participação no processo de todas as entidades e grupos que possam colaborar com a administração da justiça (GRECO, 2015, p. 299-310).

Frise-se que a questão apresenta relevância não apenas no cenário nacional, destacandose, também, internacionalmente.

Basta lembrar que, em se tratando do cenário europeu, a Convenção Europeia prevê, desde 1957, em seu artigo $6^{\circ}, \S 1^{\circ}$, a duração razoável do processo. A Itália foi, inclusive, um dos países que por diversas vezes foi acionado na Corte Europeia pela violação a uma razoável duração do processo. Inclusive, com advento da Legge Pinto (Lei n ${ }^{\circ} 89$ ), em 24 de março de 2001, que alterou 
o artigo 375 do Código de Processo Italiano, o ordenamento italiano passou a prever parâmetros para a duração do processo, com (PINHO, 2019, p. 99) um consequente procedimento compensatório caso esses parâmetros não fossem atendidos. Os parâmetros que ora se destaca e que constaram na legislação foram: i) o processo não deveria exceder um período de três anos, em primeiro grau; ii) dois anos no segundo grau durante; iii) três anos em se tratando de execução, iv) seis anos em se tratando de insolvência.

Porém, o estabelecimento de parâmetros objetivos e da compensação pecuniária não foi suficiente para solucionar o problema da duração irrazoável dos processos. Não houve mecanismos de aceleração dos processos, mas apenas a instituição de um novo procedimentos reparatório, também contencioso (SCHENK, 2008, p. 195), que emergiu o Estado Italiano em dívidas.

E o cenário de duração excessiva dos processos não é diferente na América Latina. No dia 15 de novembro de 2019, a Corte Interamericana de Direitos Humanos divulgou a condenação da Argentina por violação à duração razoável do processo no caso Perrone y Preckel Vs. Argentina. Tratava-se de dois agentes do governo que foram indevidamente detidos durante a ditadura militar argentina, sendo posteriormente presos e, um deles, Preckel, chegou a ser exilado. Buscaram a esfera administrativa e a judicial na tentativa de reparação, que, entre a etapa administrativa e a judicial, o caso demorou 13 (treze) anos e 4 (quatro) dias para ser solucionado, fixando como condenação a obrigação de publicizar a sentença e pagar uma indenização pecuniária aos agentes.

O presente trabalho não procura buscar soluções para a crise da justiça civil, mas apenas analisar o estado da arte do tema no Brasil, aferindo-se como está a duração dos processos no Poder Judiciário pátrio.

Para isso, primeiro é preciso compreender o conteúdo do que se denomina de duração razoável do processo.

Não obstante seja possível se obter informações de que a duração razoável dos processos já tenha sido medida por critérios exclusivamente quantitativos (CRUZ E TUCCI, 2008, p. 333334), referente à duração média, em meses, de cada processo, tal como foi feito pela Legge Pinto na Itália, a peculiaridade de cada demanda pode revelar diversas falhas desse critério (SANTOS, 2018, p. 21-44).

Em inúmeros julgamentos proferidos pelo Tribunal Europeu de Direitos Humanos (TEDH) sobre o tema, como nos casos König, de 10/03/1980; Bucholz, de 06/05/1981; Eckle, de 15/07/1982; Corigliano, de 10/12/1982; Pretto, de 08/12/1983; Zimmermann-Steiner, de 13/07/1983; Lechner e Hess, de 23/04/1987; Capuano, de 25/06/1987; Baggetta, de 25/06/1987; Milasi, de 25/06/1987; Sanders, de 07/07/1990; Moreiras de Azevedo, de 23/10/1990; Vernillo, de 20/02/1991, foram estabelecidos alguns critérios objetivos utilizados para determinação da duração razoável do processo, mediante o cotejo com as particularidades do caso concreto, a fim de evitar 
dilações indevidas, notadamente incidentes processuais totalmente impertinentes e irrelevantes (TUCCI, 1997, p. 68).

Os critérios estabelecidos pelo Tribunal Europeu foram: 1) a complexidade do litígio; 2) a conduta pessoal da parte lesada; 3) a conduta das autoridades envolvidas no processo; e 4) o interesse em jogo para o demandante da indenização.

Passa-se, então, a explicar cada um.

A complexidade da causa a justificar um eventual prolongamento do processo pode se dar nos casos de pluralidade de partes em razão da cumulação de pedidos, de litisconsórcios multitudinários, ser decorrente da produção probatória (critério fático) ou, ainda, em virtude da natureza da questão debatida (critério jurídico) (BERALDO, 2010, p. 39-40). Determinadas causas, a depender de sua complexidade, exigem uma análise mais detida do Poder Judiciário, um tempo maior para a tramitação dos processos do que outras.

A conduta pessoal da parte lesada significa que as próprias partes, através de uma atuação protelatória, através da provocação de incidentes dilatórios ou com a interposição de sucessivos recursos, bem como aquela que por falta de diligência não contribuiu para o seu andamento (GRECO, 2005, p. 242), podem comprometer a duração razoável do processo.

Quanto ao critério da conduta das autoridades competentes, cabe ao Estado organizar a estrutura judiciária de forma a permitir uma duração razoável dos processos. Verifica-se se as autoridades tomaram medidas apropriadas para gerenciar acúmulo temporário e imprevisível de processos. Em caso positivo, o maior tempo de processamento de alguns casos pode ser justificado.

Analisam-se, também, as peculiaridades do caso concreto, uma vez que algumas questões necessitam de uma prestação jurisdicional mais célere, tais como os que envolvem réu preso, alimentos e saúde.

Porém, paralelamente a esses critérios, a própria Comissão Europeia para eficiência da Justiça Civil (CEPEJ, 2018, p. 4-5), acabou por combinar critérios qualitativos com quantitativos, para tentar obter critérios mais adequados para o aprimoramento da prestação jurisdicional. A partir dos julgamentos da Corte Europeia de Direitos Humanos, publicou uma tabela de prazos que seriam razoáveis. Previu-se que a demora nos procedimentos, tanto cíveis como criminais, estava relacionada ao: i) congestionamento dos Tribunais; ii) insuficiência de recursos humanos; iii) existência de inúmeras decisões colegiadas durante o procedimento; iv) inércia; v) rediscussão do julgamento pelas partes; vi) existência de erros de procedimento que geravam a anulação de julgamentos.

Com a identificação e a necessidade de correção desses problemas, foi estabelecida a redução da duração razoável dos processos a cada ano. Quando se iniciou, em 2006, o prazo estipulado foi de 566 dias, que reduziu para 384 dias em 2007, aumentou para 456 dias em 2008, 
reduziu para 449 em 2009, aumentou mais um pouco para 461 em 2010 e, a partir daí, reduziu direto, apresentando números de 341 dias em 2011, 227 em 2012, 178 em 2013, 117 em 2014, 104 dias em 2015 e 106 dias em 2016, conforme dados que assim se apresentam em tabela:

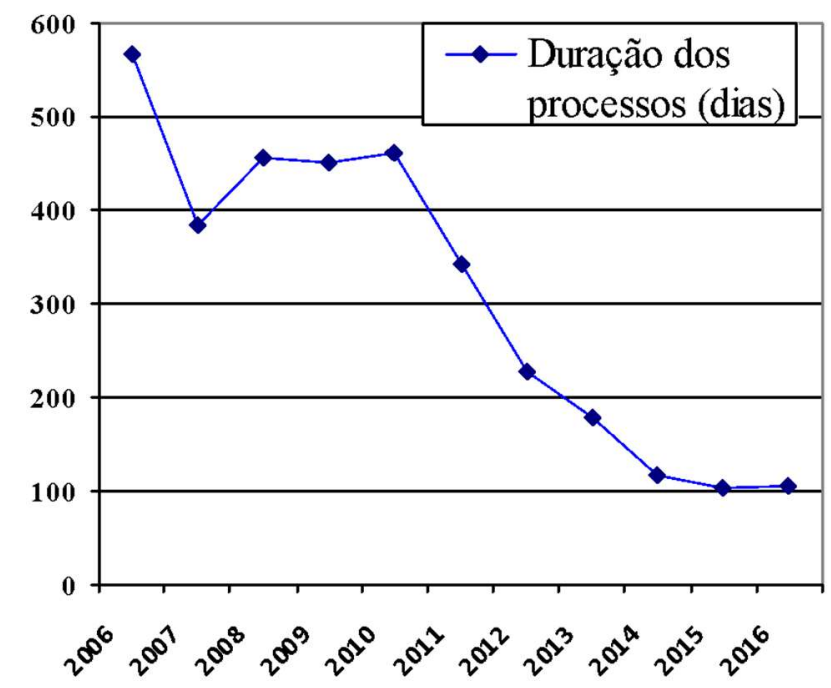

Ainda que o tempo estipulado possa sofrer variação de acordo com o país, a partir da combinação de parâmetros quantitativos e qualitativos, os dados podem ser capazes de revelar que a duração razoável do processo não constitui nem implica direito a processo rápido ou célere, mas sim implica a eliminação da desproporcionalidade entre a duração razoável do processo e a complexidade do debate da causa que nele tem lugar (MARINONI, 2016, p. 149).

A duração razoável do processo deve respeitar, portanto, a proporcionalidade entre a complexidade da causa e o tempo do processo.

A partir dessas premissas, analisam-se os institutos do Código de Processo Civil de 2015 que podem impactar na duração razoável do processo.

\section{O Código de Processo Civil de 2015}

O Código de Processo Civil de 2015, em vigor desde 18 de março de 2016, foi o primeiro código processual após a Constituição de 1988, em um período democrático, consagrando a relevância de se estabelecer uma sintonia fina com a Constituição da República Federativa do Brasil (MENDES, SILVA, 2015, p. 15-25). Passa-se, então, a analisar algumas disposições do Código de Processo Civil de 2015 à luz da garantia da duração razoável do processo. 
A democracia incute a ideia de busca do justo, que tem, no novel diploma, como um de seus destaques, inclusive, pode-se ir além e dizer que uma de suas primeiras previsões, a ênfase ao contraditório enquanto influência (artigo $9^{\circ}$ ) e da vedação das decisões-surpresa (artigo 10).

Em qualquer grau de jurisdição, o juiz não poderá decidir com base em fundamento a respeito do qual não tenha oportunizado a manifestação das partes, ainda que se trate de matéria sobre a qual deveria decidir de ofício. Excepciona-se, no texto legislativo, apenas as hipóteses de julgamento liminar de improcedência do pedido, previstas no artigo 332 do diploma, quando a parte contrária sequer integra ainda a relação processual para se manifestar.

Se, por um lado, essa disposição pode ampliar o tempo necessário para a prática dos atos processuais, por outro, pode inibir discussões ou recursos, já que as partes poderão esclarecer o que for relevante, trazendo informações necessárias ao julgamento, sem a necessidade de incidentes que alongariam o tempo de tramitação.

Frisa-se, ainda, que essa participação não pode alongar indefinidamente os julgamentos, comprometendo previsão constitucional de uma duração razoável dos processos. A aplicação das previsões deste diploma deve buscar o equilíbrio entre o contraditório enquanto participação efetiva e a duração razoável dos processos.

Outra questão que impacta na duração razoável do processo é o cômputo dos prazos processuais em dias úteis, nos termos do art. 219. A referida previsão foi, inclusive, , posteriormente, incorporada também ao artigo 12-A da Lei $\mathrm{n}^{\circ}$ 9.099/1995, através do advento da Lei ${ }^{\circ} 13.728 / 2018$, passando-se a aplicar também aos Juizados Especiais.

A medida prolonga os prazos, mas permite que os profissionais de direito possam realizar seu serviço, de modo regular, voltado para o trabalho apenas nos dias úteis. Destaca-se que essa aparentemente maior duração não é tão extensa assim, não sendo capaz de comprometer a duração razoável dos processos.

Ainda analisando a duração razoável do processo e os prazos, o Código de Processo Civil amplia, de modo geral, os prazos, o que pode repercutir na extensão do tempo de duração dos processos. Um exemplo foi a tentativa de unificação dos prazos recursais, em matéria cível, em 15 (quinze) dias, com exceção do prazo dos embargos de declaração, que, tal como preceitua o artigo 1003, $\S 5^{\circ}$ do Código de Processo Civil, permanece em 5 (cinco) dias.

Essa previsão amplia o tempo de duração do procedimento em alguns dias, mas não chega a se revelar exacerbada, ainda mais considerando que, em muitos processos, o problema identificado está fora da etapa do procedimento.

O Código de Processo Civil de 2015 a valorização dos precedentes ocorre pela própria codificação, que tenta implementar a valorização dos julgamentos dos tribunais, sobretudo superiores. Como constou no relatório do Senador Vital do Rêgo, "o respeito aos precedentes 
jurisprudenciais é uma das marcas do futuro Código, o que reduzirá o grau de imprevisibilidade jurídica que impera sobre os atores da vida civil" (SENADO FEDERAL, 2015, p. 2).

Nesse diapasão, o artigo 926 indica que a jurisprudência dos tribunais deve se manter íntegra, coerente e estável, em uma nítida da previsão de que os tribunais devem respeitar seus precedentes e dar-lhes publicidade. Além disso, em nítida valorização do julgamento dos Tribunais, sobretudo dos Tribunais Superiores, o artigo 927 prevê a existência de precedentes vinculantes, a serem observados pelos julgadores (MENDES, 2017, p. 119-130).

No que tange à duração razoável do processo, do ponto de vista macro, a vinculação ao precedente judicial pode significar uma celeridade maior, porque, com o acolhimento dos precedentes judiciais no julgamento, há uma tendência à coerência, à integridade e à estabilidade dos julgamentos e, como consequência, também uma tendência à redução do número de recursos e à redução da tramitação dos processos a partir do ajuizamento de causas em que haja teses já fixadas, com a diminuição no tempo de tramitação os processos.

Ademais, com a fixação da tese e sua aplicação a alguns processos, o Poder Judiciário poderá se dedicar mais tempo a causas que não sejam padronizadas, permitindo que os julgadores possam ficar mais atentos ao conteúdo dos processos.

Outra modificação que pode trazer impacto na duração razoável do processo é a própria técnica de julgamento, prevista no art. 942, que dispõe, em determinadas situações, dispostas em seu caput e $\S 3^{\circ}$, sobre o prosseguindo o julgamento não unânime em outra sessão próxima, salvo se possível na mesma sessão, com a presença de outros julgadores, em número suficiente para garantir a possibilidade de inversão do resultado inicial, ofertando-se nova sustentação oral para as partes (SILVA, 2018, p. 63-79).

No âmbito dos Tribunais de Justiça (TJs) e Tribunais Regionais Federais (TRFs), essa técnica alongará o julgamento das decisões por maioria em alguns dias, mas servirá para aprimorar o debate, reduzindo os recursos para os tribunais superiores.

Prosseguindo em relação aos processos nos tribunais, há uma modificação significativa, porque o juízo de admissibilidade dos recursos, com exceção dos recursos especial e extraordinário, será realizado pelo órgão ad quem, e não mais no órgão $a$ quo.

No que tange à duração razoável do processo, o exame da admissibilidade recursal realizado pelo órgão ad quem, agiliza a remessa do recurso ao tribunal, mas, alonga o tempo de tramitação de recursos intempestivos ou de outras hipóteses de inadmissibilidade.

O incidente de resolução de demandas repetitivas (IRDR) e os recursos repetitivos são procedimentos para julgamentos de casos repetitivos, que se referem a questões comuns de direito, capazes de proporcionar grave insegurança jurídica, devido ao risco de decisões contraditórias. Os instrumentos possuem a perspectiva de trazer racionalização e eficiência diante dos conflitos de 
massa, evitando que haja ofensa à isonomia e à segurança jurídica nos julgamentos de questões comuns de direito, material ou processual (MENDES, 2017, p. 1).

Caso haja a suspensão dos processos individuais ou coletivos pendentes, por até um ano até a decisão a ser proferida, poderá haver uma maior morosidade aos processos. Porém, em tese, a médio e longo prazo, o efeito desse novel mecanismo será a racionalização do sistema processual, já que a tese jurídica firmada será aplicada, ressalvada a possibilidade de sua revisão, nos termos da nova previsão legislativa, a todos os processos individuais ou coletivos que versem sobre idêntica questão de direito e que tramitem na área de jurisdição do respectivo tribunal, bem como aos casos futuros, o que poderá proporcionar celeridade aos processos.

Considerando a existência desses mecanismos e da análise teórica dos possíveis impactos na duração razoável dos processos, passa-se a analisar o reflexo das disposições do código no tempo médio de tramitação dos processos, realizando-se um balanço após sua vigência.

\section{Os impactos do Código no tempo médio de tramitação dos processos}

\subsection{Os dados sobre a duração razoável do processo}

O Conselho Nacional de Justiça (CNJ) adota algumas métricas para o cálculo da duração dos processos no Brasil em suas divulgações sobre o Programa Justiça em Números.

Segundo dados divulgados no ano de 2019, mas coletados em 2018, no âmbito da Justiça Estadual, a maior duração do processo, em primeiro grau de jurisdição, estava no Tribunal de Justiça do Estado do Amazonas, que apresentou uma média de 5 anos e 8 meses para julgamento, enquanto, em segundo grau de jurisdição, o maior tempo foi do Tribunal de Justiça do Pará, com duração de 1 ano e 11 meses. A média da Justiça Estadual foi de 3 anos e 7 meses em primeiro grau de jurisdição e 8 meses em segundo grau de jurisdição.

Os dados são assim sintetizados (CNJ, 2019, p. 153): 


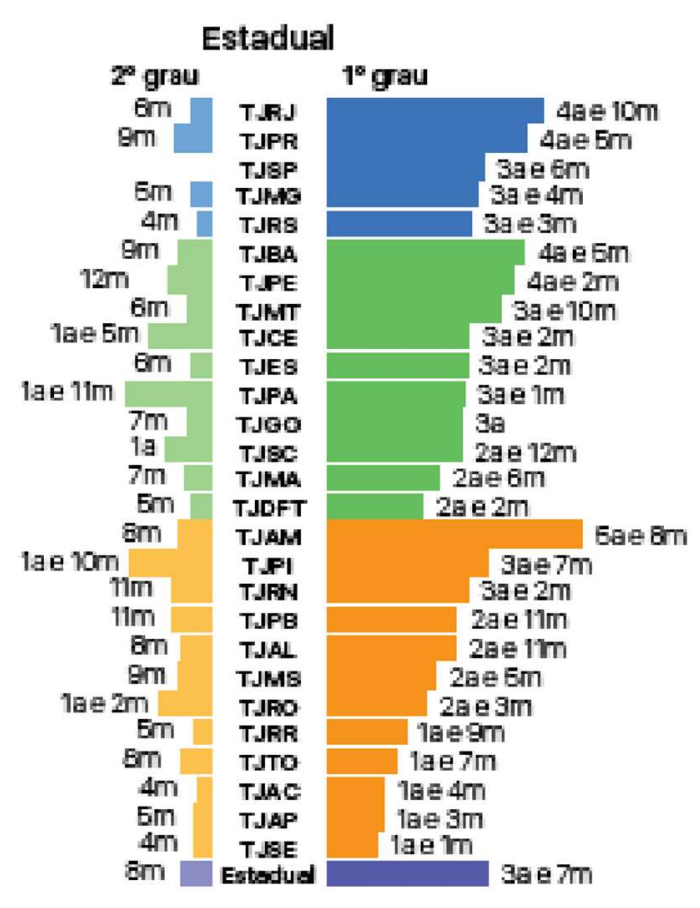

Já no âmbito da Justiça Federal, o maior prazo em primeiro grau foi localizado no Tribunal Regional Federal da Segunda Região, que apresentou o prazo de 6 anos e 8 mês para julgamento, enquanto, em segundo grau, o Tribunal Regional Federal da Primeira Região teve duração de 3 anos e 1 mês. A média da Justiça Federal foi de 4 anos e 6 meses no primeiro grau e de 2 ano e 2 meses no segundo grau.

Os dados são assim esquematizados pelo Conselho Nacional de Justiça (CNJ, 2019, p.153):

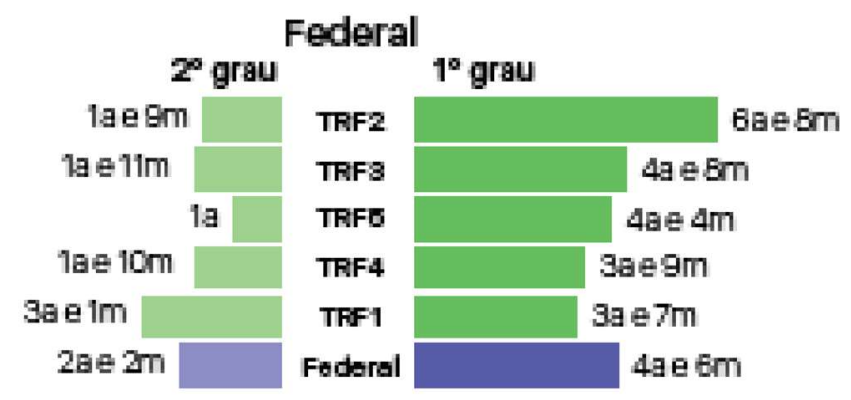

Segundo dados divulgados no ano de 2018, mas coletados em 2017, no âmbito da Justiça Estadual, a maior duração do processo, em primeiro grau de jurisdição, estava no Tribunal de Justiça do Estado do Rio Grande do Norte, que apresentou uma média de 10 anos e 11 meses para julgamento, enquanto, em segundo grau de jurisdição, o maior tempo foi do Tribunal de Justiça do 
Pará, com duração de 1 ano e 11 meses. A média da Justiça Estadual foi de 3 anos e 9 meses em primeiro grau de jurisdição e 8 meses em segundo grau de jurisdição.

Os dados obtidos foram assim sintetizados pelo Conselho Nacional de Justiça (CNJ, 2018, p. 142):

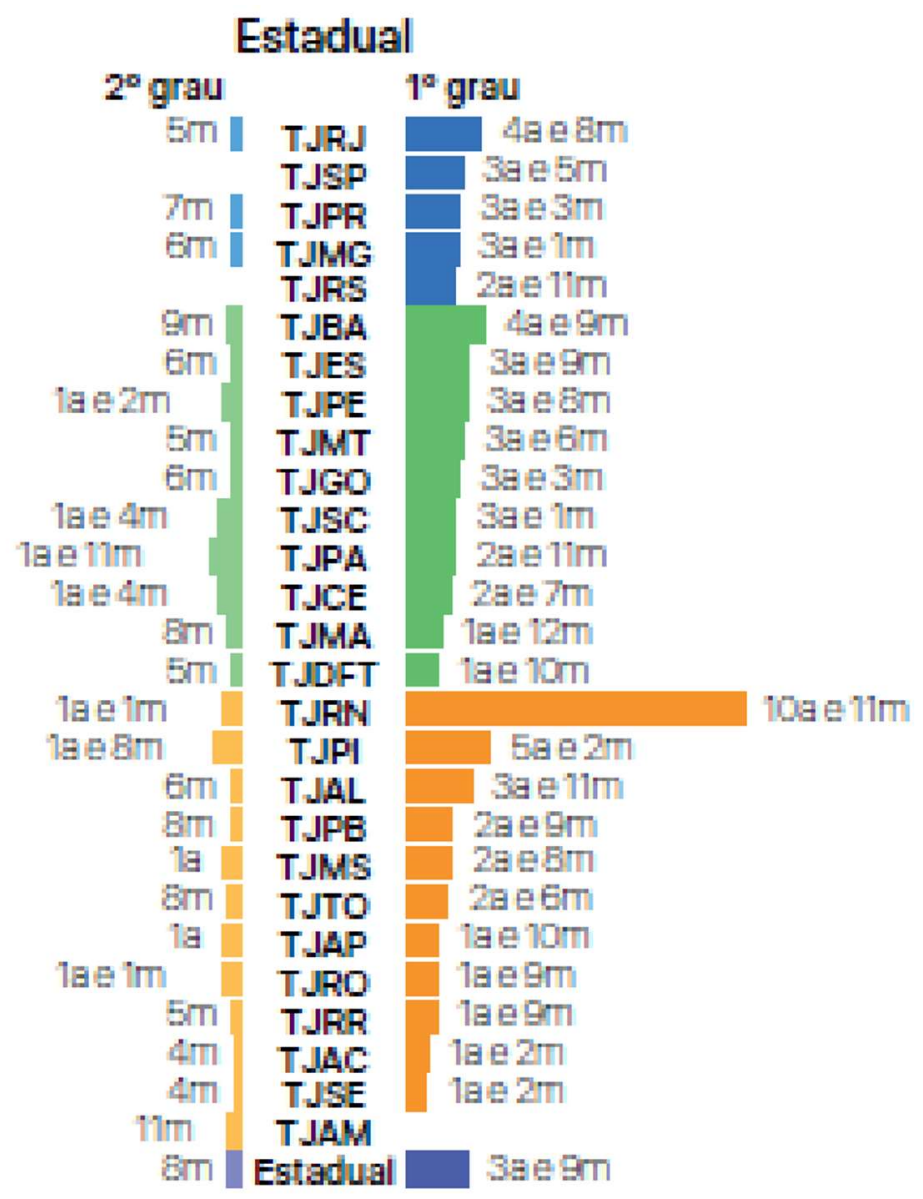

Já no âmbito da Justiça Federal, o maior prazo em primeiro grau foi localizado no Tribunal Regional Federal da Terceira Região, que apresentou o prazo de 5 anos e 1 mês para julgamento, enquanto, em segundo grau, o Tribunal Regional Federal da Primeira Região teve duração de 2 anos e 5 meses. A média da Justiça Federal foi de 4 anos e 3 meses no primeiro grau e de 1 ano e 11 meses no segundo grau.

Os dados são assim esquematizados pelo Conselho Nacional de Justiça (CNJ, 2018, p. 151): 


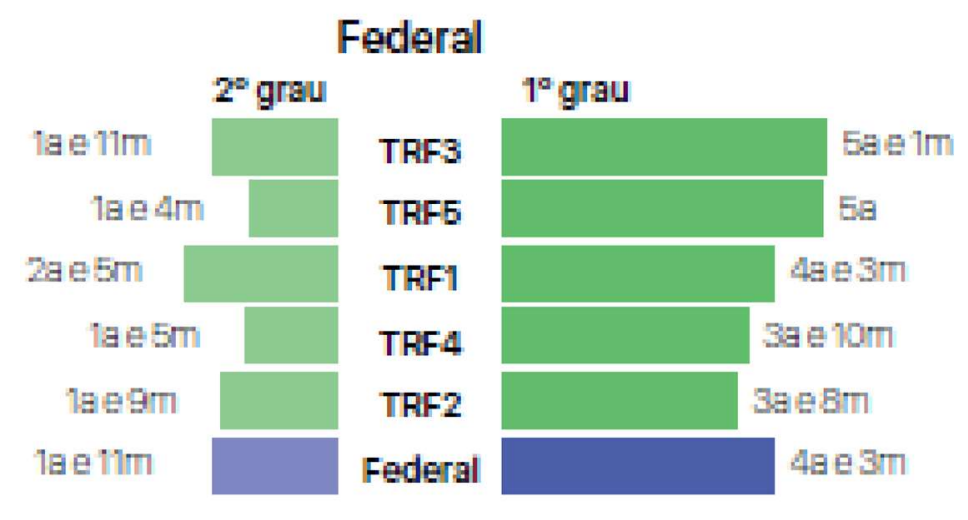

No ano de 2017, tendo como base o ano de 2016, ano em que entrou em vigor o Código de Processo Civil de 2015, o tempo mais longo de tramitação foi no Tribunal de Justiça da Bahia, que demorou, em média, 4 anos e 3 meses em primeiro grau de jurisdição, mas, em segundo grau, o maior tempo foi do Tribunal de Justiça do Piauí, com 1 ano e 5 meses de duração. A média da Justiça Estadual foi de 3 anos e 2 meses em primeiro grau e 7 meses em segundo grau.

Nesse sentido (CNJ, 2018, p. 131):

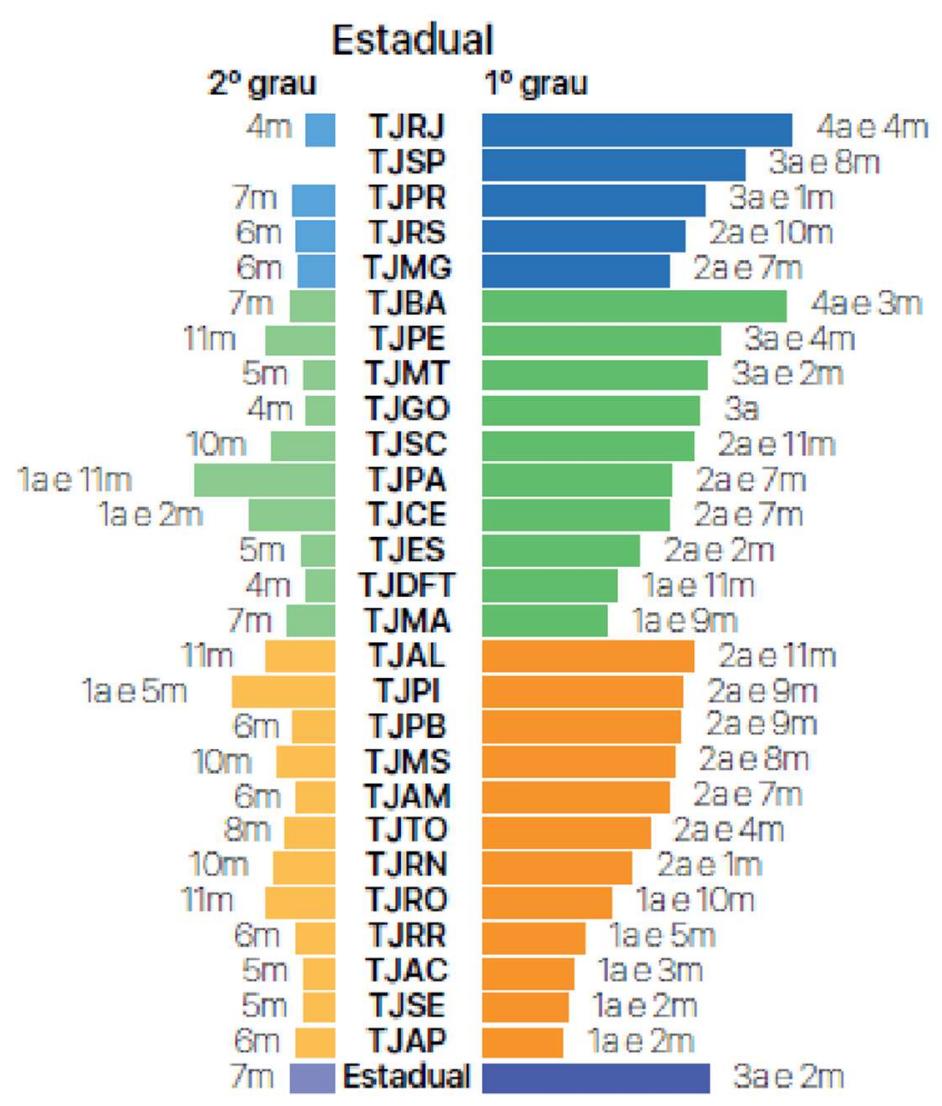


Por sua vez, na Justiça Federal, o Tribunal Regional Federal da Terceira Região teve o maior tempo de duração em primeiro grau, de 4 anos e 8 meses, enquanto o Tribunal Regional Federal da Primeira Região teve o maior tempo de duração em segundo grau, de 2 anos e 8 meses. A média da Justiça Federal foi de 4 anos e 2 meses em primeiro grau e de 1 ano e 10 meses em segundo grau.

Os dados são assim esquematizados pelo Conselho Nacional de Justiça (CNJ, 2017, p. 137):

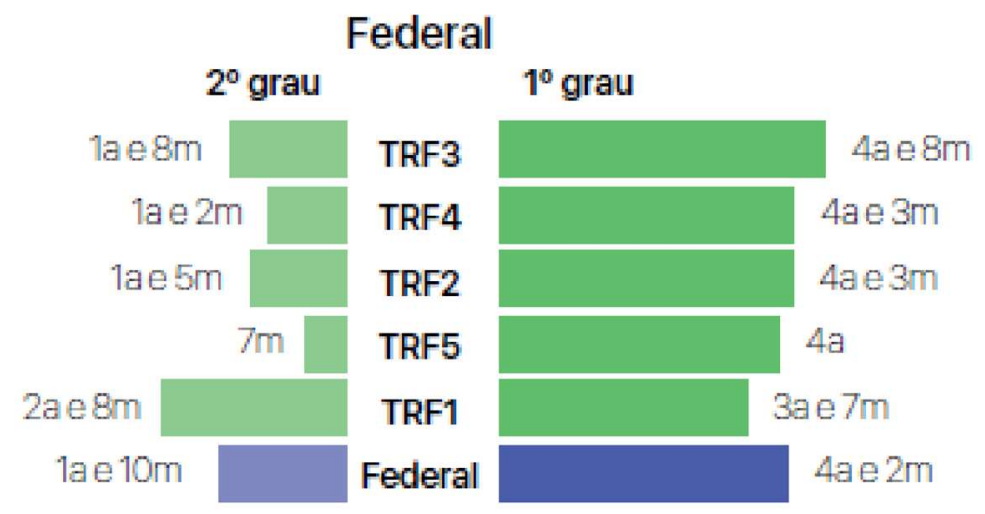

Os dados até então expostos se referem ao período de vigência do Código de Processo Civil de 2015. Anteriormente à vigência do diploma, as estatísticas do Conselho Nacional de Justiça (CNJ) não forneciam os dados por Tribunal. Porém, é possível se constatar que, no ano de 2016, ano-base 2015, o tempo médio de tramitação dos processos na Justiça Estadual, em primeiro grau, era de 1 ano e 11 meses e no Tribunal era de 6 meses, enquanto na Justiça Federal o tempo de 1 anos e 8 meses para julgamento foi o mesmo em primeiro e segundo grau. Antes desse período, a empresa não fornecia os dados em relação ao tempo de tramitação de processos.

Passa-se, então, a analisar os dados à luz dos conceitos expostos.

\subsection{Os reflexos do diploma na duração razoável do processo}

Em relação ao ano anterior à vigência do Código de Processo Civil de 2015 para os anos de sua vigência, nota-se que o tempo de tramitação dos processos durante a vigência do Código aumentou em primeiro e segundo grau, tanto na Justiça Estadual como na Justiça Federal.

Esse aumento pode, dentre alguns fatores, ser associado a ênfase ao contraditório, à ampliação dos prazos, sobretudo a contagem dos prazos em dias úteis e a unificação dos prazos recursais em 15 (quinze) dias, a ampliação do colegiado prevista no artigo 942 e a suspensão dos processos para que sejam firmadas teses com eficácia vinculante. 
Já nos primeiros anos de vigência do diploma, referentes ao período de 2017 (ano-base 2016) a 2019 (ano-base 2018), pode-se, ainda, constatar, a partir dos gráficos fornecidos pelo Conselho Nacional de Justiça (CNJ) que, com exceção da Justiça Federal de Segunda Instância, que apresentou um aumento significativo do tempo de duração dos processos de 2018 para 2019, o tempo médio de duração dos processos se manteve razoavelmente estável durante a vigência do novel diploma.

Esses primeiros anos de vigência possuem uma estabilidade até esperada, porque ainda é o período de aplicação dos novos institutos e de fixação de entendimentos que, quando começarem a ser aplicados, poderão reduzir o prolongamento do tempo dos processos, evitando-se recursos desnecessários.

Assim, não obstante as previsões do novel diploma tenham gerado um tempo de tramitação ao que os dados indicam maior ao processo, o respeito às garantias processuais e a valorização dos julgamentos dos tribunais, sobretudo superiores, com a fixação de teses jurídicas e o fortalecimento do respeito aos precedentes, nos próximos anos, espera-se que, caso haja a correta aplicação das previsões do novel diploma, com especial atenção ao tempo de suspensão dos processos para a fixação de teses jurídicas e a adequada aplicação das teses já fixadas, a perspectiva seja de, anualmente, ocorrer a redução do tempo de tramitação dos processos, até que, a médio e longo prazo, seja possível se perceber um lapso temporal significativamente menor ao anterior à vigência do diploma para que haja a prestação jurisdicional definitiva.

\section{Conclusão}

O longo tempo de tramitação dos processos não é um problema atual e nem restrito ao Brasil, mas que se agrava na medida que se amplia o número de demandas que ingressam no Poder Judiciário, em descompasso com o quantitativo de recursos materiais e humanos.

Uma das dificuldades do problema é a própria conceituação do que seria a duração razoável do processo e a outra, sem dúvida, é como alcançar um tempo de tramitação razoável.

A duração razoável dos processos somente pode ser prevista quando se associam critérios qualitativos, como a complexidade do litígio; a conduta pessoal da parte lesada; a conduta das autoridades envolvidas no processo; e o interesse em jogo para o demandante da indenização, com critérios quantitativos.

Quando se trata de Brasil, durante a vigência do Código de Processo Civil, pode-se constatar, a partir de dados do Conselho Nacional de Justiça (CNJ), que o tempo de tramitação dos processos aumentou tanto na Justiça Estadual, como na Justiça Federal, em primeiro e segundo graus. Esse aumento, durante o primeiro ano de vigência, foi de 1 ano e 3 meses em primeiro grau 
e 1 mês em segundo grau, na Justiça Estadual. Já na Justiça Federal foi de 2 anos e 4 meses em primeiro grau e de 2 meses em segundo grau o aumento do tempo de tramitação dos processos. No segundo ano, o aumento foi de 2 anos e 10 meses em primeiro grau e 2 meses em segundo grau na Justiça Estadual, caso comparado ao período anterior à vigência do novel diploma e de 2 anos e 7 meses em primeiro grau e 3 meses em segundo grau na Justiça Federal caso comparado o segundo ano de vigência do diploma com o período anterior à sua vigência. Já no terceiro ano, quando, com exceção da Justiça Federal de segundo grau, os dados se mantiveram razoavelmente estáveis, o tempo de duração médio foi de 3 anos e 7 meses na Justiça Estadual em primeira instância, 8 meses na Justiça Estadual de segunda instância, 4 anos e 6 meses na Justiça Federal de primeira instância e 2 anos e 2 meses na Justiça Federal de segunda instância.

Apesar de o período após a entrada em vigor do novo diploma ter indicado um aumento no tempo de tramitação dos processos, relacionado ao respeito às garantias processuais e à valorização dos julgamentos dos tribunais, sobretudo superiores, com a fixação de teses jurídicas e o fortalecimento do respeito aos precedentes, a expectativa é a de que, caso haja a correta formação e aplicação dos precedentes, anualmente possa ocorrer a redução do tempo de tramitação dos processos, até que, a médio e longo prazo, seja possível se perceber um lapso temporal significativamente menor ao anterior à vigência do diploma.

\title{
THE IMPACTS OF THE CIVIL PROCEDURE CODE IN REASONABLE DURATION OF PROCESS: A BALANCE OF ITS TERM
}

\begin{abstract}
The present article aims to analyze the impacts brought by the Code of Civil Procedure of 2015 in the length of claims. Initially, it seeks to portray the meaning of the theme that will be addressed, that is, the reasonable duration of the process, indicating the insufficiency of merely quantitative criteria. It then highlights provisions of the Civil Procedure Code of 2015 that may interfere with the reasonable duration of the process and, afterwards, based on data from the National Council of Justice (CNJ), covering the previous year and the period of validity of the procedural law, the paper interprets the change of the length of claims, indicating that, even in the first years of the codex, claim's length has considerably increased, the prospect is it will be reduced in the medium term of the claims.
\end{abstract}

Keywords: Reasonable length of claims; Civil Procedure Code of 2015; impacts; balance; prospects.

\section{Referências}

BARBOSA MOREIRA, José Carlos. O problema para a duração dos processos: premissas para uma discussão séria. Temas de direito processual. São Paulo: Saraiva, 9a série, 2007. 
BERALDO, Maria Carolina Silveira. O comportamento dos sujeitos processuais como obstáculo à razoável duração do processo. Dissertação (Mestrado em Direito) - Faculdade de Direito da Universidade de São Paulo, 2010.

CONSELHO NACIONAL DE JUSTIÇA. Justiça em números. CNJ: 2019. Disponível em https://www.cnj.jus.br/wpcontent/uploads/conteudo/arquivo/2019/08/justica_em_numeros20190919.pdf. Acesso em 17 jan. 2020 .

Justiça em números. CNJ: 2018. Disponível em http://www.cnj.jus.br/files/conteudo/arquivo/2018/08/44b7368ec6f888b383f6c3de40c32167.pdf. Acesso em 26 mar. 2019.

Justiça em números. CNJ: 2017, p. 131-137. Disponível em http://www.cnj.jus.br/files/conteudo/arquivo/2017/12/b60a659e5d5cb79337945c1dd137496c.pdf. Acesso em 26 mar. 2019.

Justiça em números. CNJ: 2016. Disponível em http://www.cnj.jus.br/files/conteudo/arquivo/2016/10/b8f46be3dbbff344931a933579915488.pdf. Acesso em 26 mar. 2019.

EUROPEAN COMISSION FOR THE EFFICIENCY OF JUSTICE (CEPEJ). Length of court proceedings in the member states of the Council of Europe based on the case law of the European Court of Human Rights. Estraburgo: CEPEJ, 2018, 3.ed., p. 4-5. Disponível em https://rm.coe.int/cepej-2018-26-en-rapport-calvez-regis-en-length-of-court-proceedingse/16808ffc7b. Acesso em 24 mar. 2019. GAJARDONI, Fernando da Fonseca. Técnicas de aceleração do processo (uma análise crítica à luz de dados estatísticos). Dissertação (Mestrado em Direito) - Faculdade de Direito da Universidade de São Paulo, 2002.

GRECO, Leonardo. Contraditório efetivo (art. $7^{\circ}$ ). Revista Eletrônica de Direito Processual REDP. Rio de Janeiro: UERJ, vol. 15, jan.-jun. 2015.

. Garantias fundamentais do processo: O processo justo. Estudos de Direito Processual. Rio de Janeiro: Faculdade de Direito de Campos, 2005, p. 225-286.

MARINONI, Luiz Guilherme. Novo Código de Processo Civil comentado. 2. ed. São Paulo: Revista dos Tribunais, 2016.

MENDES, Aluisio Gonçalves de Castro. Ações coletivas e meios de resolução coletiva de conflitos no direito comparado e nacional. São Paulo: RT, 4.ed., 2014.

. Breves considerações sobre o caráter vinculativo da jurisprudência e dos precedentes no artigo 927 do novo Código de Processo Civil. In: Dierle Nunes; ; Fernando Gonzaga Jayme. (Org.). A nova Aplicação da Jurisprudência e Precedentes no CPC/2015. Estudos em Homenagem à Professora Teresa Arruda Alvim. 1ed.São Paulo: Revista dos Tribunais, 2017, p. 119-130. 
. Incidente de Resolução de Demandas Repetitivas: Sistematização, análise e interpretação do novo instituto processual. 1. ed. Rio de Janeiro: Gen/Forense, 2017.

; SILVA, Larissa Clare Pochmann. Os impactos do novo CPC na razoável duração do processo. Revista de Processo. São Paulo: RT, v. 241, 2015, p. 15-25.

PINHO, Humberto Dalla Bernardina de. Manual de Direito Processual Civil Contemporâneo. São Paulo: Saraiva, 2019.

SANTOS, Paula Ferraresi. Duração razoável do processo: critérios para seu dimensionamento e aplicação no Brasil. Revista de Processo. São Paulo: RT, vol. 277, mar. 2018.

SCHENK, Leonardo Faria. Breve relato histórico das reformas processuais na Itália. Um problema constante: A lentidão dos processos cíveis. Revista Eletrônica de Direito Processual - Ano 2, Volume II, Rio de Janeiro, 2008, p. 181-202.

SENADO FEDERAL. Relatório do projeto do Código de Processo Civil. http://www.senado.leg.br/atividade/materia/getPDF.asp? $t=157517 \& t p=1$. Acesso em 9 dez. 2019.

SILVA, L. C. P. O Artigo 942 do Código de Processo Civil de 2015. REVISTA MAGISTER DE DIREITO CIVIL E PROCESSUAL CIVIL, v. XIV, p. 63-79, 2018.

TUCCI, José Rogério Cruz e. Duração razoável do processo. In: MARTINS, Ives Gandra da Silva; JOBIM, Eduardo (Coord.). O processo na Constituição. São Paulo: Quartier Latin, 2008.

. Tempo e processo: uma análise empírica das repercussões do tempo na fenomenologia processual (civil e penal). Ed. São Paulo: RT, 1997.

ZUCKERMAN, Adrian. Civil Justice in Crisis: Comparative Perspectives of Civil Procedure. Oxford: Oxford University Press, 2013. 